\title{
Pelatihan penggunaan aplikasi Paint dan pembuatan blog untuk meningkatkan kreatifitas pendidik pada HIMPAUDI Batam Center
}

\author{
Nurul Azwanti ${ }^{\mathbb{D}}{ }^{*}$, Alfannisa Annurullah Fajrin, dan Yopy Mardiansyah \\ Universitas Putera Batam \\ *nurulazw@rocketmail.com
}

\begin{abstract}
Pendidikan Anak Usia Dini (PAUD) is the implementation of education before entering basic education to help growth and physical and spiritual development so that children have readiness in entering further education. The Association of Indonesian Early Childhood Educators and Education Personnel or abbreviated as HIMPAUDI is an organization of PAUD educators to increase the effectiveness of every PAUD teacher. Given the importance of the creativity of PAUD educators, HIMPAUDI Batam Center needs to make various innovative efforts to improve the quality of students and education itself. In this technological era, all forms of activities especially those related to teaching have turned to modern in order to keep up with the times. If only PAUD teachers feel that there is no need for creativity by not following technological developments especially considering that they have mastered learning in the classroom, then the educator will miss all the knowledge that is still embedded without being explored further using information technology. This service will provide training for PAUD teachers to innovate and increase their creativity without having to be outdated. Utilizing applications that are available free of charge and creating blogs as "space" for teachers to share will be an activity in this service.
\end{abstract}

\begin{abstract}
Abstrak Pendidikan Anak Usia Dini (PAUD) adalah pelaksanaan pendidikan sebelum memasuki pendidikan dasar untuk membantu pertumbuhan dan perkembangan jasmani dan rohani agar anak memiliki kesiapan dalam memasuki pendidikan lebih lanjut. Himpunan Pendidik dan Tenaga Kependidikan Anak Usia Dini Indonesia atau disingkat dengan HIMPAUDI merupakan sebuah organisasi para pendidik PAUD untuk meningkatkan efektifitas setiap guru PAUD. Mengingat pentingnya kreatifitas pendidik PAUD, HIMPAUDI Batam Center perlu melakukan berbagai upaya inovasi untuk meningkatkan kualitas anak didik maupun untuk pendidikan itu sendiri. Di era teknologi ini, segala bentuk kegiatan apalagi yang berhubungan dengan pengajaran sudah beralih ke modern guna mengikuti perkembangan zaman. Jika saja para guru PAUD merasa tidak perlu untuk berkreatifitas dengan tidak mengikuti perkembangan teknologi apalagi menganggap sudah menguasai pembelajaran di dalam kelas, maka pendidik tersebut akan ketinggalan dengan segala ilmu yang masih tertanam tanpa dieksplor lebih jauh lagi dengan menggunakan teknologi informasi. Pengabdian ini akan memberikan pelatihan bagi guru PAUD untuk berinovasi dan meningkatkan kreatifitasnya tanpa harus ketinggalan zaman. Pemanfaatan aplikasi yang tersedia gratis serta pembuatan blog sebagai "ruang" bagi guru untuk berbagi akan menjadi kegiatan dalam pengabdian ini.
\end{abstract}

Keywords: training; Paint; blog; creativity; educator

\section{ठ OPEN ACCESS}

Citation: Azwanti, N., A.A. Fajrin, dan Y. Mardiansyah. 2019. Pelatihan penggunaan aplikasi Paint dan pembuatan blog untuk meningkatkan kreatifitas pendidik pada HIMPAUDI Batam Center. Riau Journal of Empowerment 2(1): 9-13 https://doi.org/10.31258/raje.2.1.14

Received: 2019-01-21 Revised: 2019-04-12 Accepted: 2019-05-21

Language: Bahasa Indonesia (id)

Funding: LPPM Universitas Putera Batam

(c) 2019 Nurul Azwanti et al. The article by Author(s) is licensed under a Creative Commons Attribution 4.0 International License. This license permits unrestricted use, distribution, and reproduction in any medium, provided the original author and source are credited. 


\section{PENDAHULUAN}

Pendidikan Anak Usia Dini (PAUD) adalah pelaksanaan pendidikan sebelum memasuki pendidikan dasar, hal ini merupakan upaya pembinaan yang ditujukan bagi anak sejak lahir sampai dengan usia enam tahun yang dilakukan melalui pemberian rangsangan pendidikan untuk membantu pertumbuhan dan perkembangan jasmani dan rohani agar anak memiliki kesiapan dalam memasuki pendidikan lebih lanjut. Dalam pelaksanaannya, guru sebagai tenaga pendidik dituntut untuk memberikan layanan yang lebih profesional, mengingat perkembangan setiap anak berbeda-beda. Guru PAUD memberikan dampak yang lebih besar bagi siswa PAUD untuk tumbuh dan berkembang dengan baik.

Himpunan Pendidik dan Tenaga Kependidikan Anak Usia Dini Indonesia atau biasa disingkat dengan HIMPAUDI merupakan sebuah organisasi para pendidik PAUD untuk meningkatkan efektifitas setiap guru PAUD. Terbentuknya HIMPAUDI diharapkan dapat: 1) Menjadi wadah bagi para pendidik dan tenaga kependidikan untuk saling asah, asih dan asuh dalam rangka meningkatkan mutu program pendidikan anak usia dini secara optimal di seluruh Indonesia; dan 2) Mengoptimalkan pemahaman dan pengembangan pengetahuan serta keterampilan tentang program pendidikan anak usia dini yang selama ini dirasa masih kurang (Tedjawati, 2011). Salah satunya adalah HIMPAUDI Batam Center yang merupakan himpunan untuk wilayah Batam Center, Kota Batam. HIMPAUDI Batam Center beranggotakan sekitar 30 orang dan telah banyak melakukan berbagai kegiatan diantaranya mensosialisasikan PAUD yang berkualitas, melakukan pembinaan serta meningkatkan dan memfasilitasi pengembangan profesi pendidik dan tenaga kependidikan anak usia dini.

Mengingat pentingnya kreatifitas pendidik PAUD, HIMPAUDI Batam Center perlu melakukan berbagai upaya inovasi untuk meningkatkan kualitas anak didik maupun untuk pendidikan itu sendiri. Kreatifitas diindentikkan dengan menemukan sesuatu yang baru atau memodifikasi yang telah ada menjadi sesuatu yang baru. Jadi tidak selalu harus benar-benar baru (Miranda, 2016). Guru pendidik anak usia dini harus dapat menemukan berbagai cara agar dapat menyajikan keseluruhannya dengan cara berbeda dan tentunya harus dapat menyenangkan untuk Anak Usia Dini (Sopiah, 2014). Adapun bentuk dari kreatifitas tersebut berupa keahlian atau kemampuan yang dimilikinya yang merupakan didapatkan dari proses belajar baik dari pendidikan formal atau non formal yang diikuti oleh seseorang. Dari proses belajar akan memberikan perubahan yang mendasarkan pada kemampuan berupa daya pikir dan perbuatan (Febrialismanto, 2017).

Di era teknologi ini, segala bentuk kegiatan apalagi yang berhubungan dengan pengajaran sudah beralih ke modern guna mengikuti perkembangan zaman. Jika saja para guru PAUD merasa tidak perlu untuk berkreatifitas dengan tidak mengikuti perkembangan teknologi apalagi menganggap sudah menguasai pembelajaran di dalam kelas, maka pendidik tersebut akan ketinggalan dengan segala ilmu yang masih tertanam tanpa dieksplor lebih jauh lagi dengan menggunakan teknologi informasi. Sebagai contoh bisa kita lihat pada saat anak didik disuruh untuk menggambar ataupun mewarnai. Media kertas mungkin dianggap terlalu biasa dan tidak memiliki daya tarik bagi anak-anak, sehingga bagi anak-anak akan cepat bosan dan mengantuk. Selain itu, guru pendidik juga tidak memiliki "ruang" untuk membagikan kreatifitasnya dengan rekan seprofesi. Misalnya ingin memberikan tips dan trik mengajar yang menyenangkan, membagikan hasil mewarnai dari aplikasi yang digunakan dan kegiatan lainnya. Tidak tersedianya "ruang" inilah yang akan membuat para pendidik PAUD seperti jalan ditempat.

Ada banyak aplikasi yang bisa dimanfaatkan untuk memberikan daya tarik ketika mengajar, diantaranya adalah aplikasi Paint. Paint memiliki tools yang sangat dasar dan mudah digunakan untuk pengguna yang tidak terbiasa dengan komputer. Berdasarkan permasalahan yang telah diuraikan di atas, maka pengabdian ini akan memberikan pelatihan bagi guru PAUD untuk berinovasi dan meningkatkan kreatifitasnya tanpa harus ketinggalan zaman. Selain itu, sebagai penunjang dari kegiatan sebagai pendidik, perlu adanya blog yang akan dimanfaatkan "ruang" bagi guru untuk berbagi ilmu. 


\section{METODE PENERAPAN}

Azwanti dkk

Untuk memperoleh manfaat dari pengabdian ini metode penerapan yang akan dilakukan adalah a) Mengenalkan tentang teknologi informasi; b) Mengenalkan aplikasi Paint beserta manfaat dan kegunaannya; c) Menjelaskan tools yang ada di Paint; d) Mempraktekkan menggambar di Paint; e) Mempraktekkan menyimpan hasil gambar; f) Mempraktekkan menggambar dan open file di Paint; g) Mempraktekkan cara mewarnai di Paint; h) Mempraktekkan menyimpan hasil mewarnai

Pada hari keduanya, peserta akan melanjutkan lagi materi dengan pokok pembahasan antara lain: a) Menjelaskan mengenai internet dan blog; b) Mempraktekkan membuat akun email; c) Mempraktekkan membuat blog; d) Mempraktekkan meng-edit dan memperbaharui blog; e) Mempratekkan membuat tulisan di blog dan mem-publish tulisan di blog; f) Mempraktekkan mengimpor file gambar di blog.

Adapun susunan acara untuk pelaksanaan kegiatan ini, dapat dilihat pada Tabel 1.

Tabel 1. Susunan Pelaksanaan Kegiatan

\begin{tabular}{ll}
\hline Waktu (WIB) & \multicolumn{1}{c}{ Kegiatan } \\
\hline $14.00-14.10$ & Pembukaan \\
$14.10-14.20$ & Sambutan dari Ketua Pengabdian Masyarakat \\
$14.20-14.30$ & Sambutan dari Perwakilan HIMPAUDI Batam Center \\
$14.30-16.00$ & Pemberian Materi dan Praktek dari Tim Pengabdi \\
$16.00-16.30$ & Tanya Jawab dan Penutupan \\
\hline
\end{tabular}

Berdasarkan Tabel 1 diatas dipaparkan untuk kegiatan awal dimulai sekitar pukul 14.00 WIB untuk pembukaan dan dilanjutkan sambutan dari ketua pengabdian masyarakat guna terlaksananya pengabdian dengan baik dan lancar. Kemudian dilanjutkan sambutan dari perwakilan HIMPAUDI Batam Center untuk memberikan masukan acara pengabdian yang akan berlangsung. Selanjutnya dari tim pengabdi akan bergantian memberikan materi pengabdian dan praktek yang diikuti oleh peserta. Kegiatan terakhir melakukan tanya jawab dari seputar materi yang diberikan dan diakhiri dengan penutupan. Kegiatan ini berlangsung 2 kali sesuai waktu dan tempat pelaksanaan yang telah ditentukan.

\section{HASIL DAN KETERCAPAIAN SASARAN}

\section{Hasil Pengabdian}

Hasil pengabdian yang telah dilaksanakan didapatkan bahwa anggota HIMPAUDI Batam Center memiliki keinginan yang kuat dalam belajar terutama dalam bidang teknologi informasi. Motivasi terbesar dari pengabdi adalah mampu memberikan dan membagikan ilmu yang dimiliki sehingga dapat mengatasi permasalahan yang sering timbul didalam masyarakat terkait bidang teknologi informasi. Adapun hasil pengabdian yang telah dilaksanakan akan dirangkum ke dalam poin-poin berikut ini:

a. Berdasarkan materi yang diberikan, para peserta pengabdian memahami maksud dari tujuan pengabdian ini. Dua materi yang diberikan memang tidak memiliki keterkaitan secara langsung, namun dapat menambah pengetahuan para peserta.

b. Adanya hubungan timbal balik antara pengabdi dengan peserta dalam bentuk tanya jawab, diyakini bahwa pengabdian ini sangat membantu para peserta untuk memberikan sebuah inovasi untuk pembelajarannya.

c. Target dari keikutsertaan para anggota HIMPAUDI sudah terpenuhi dan menunjukan antusiasme dari para peserta. 


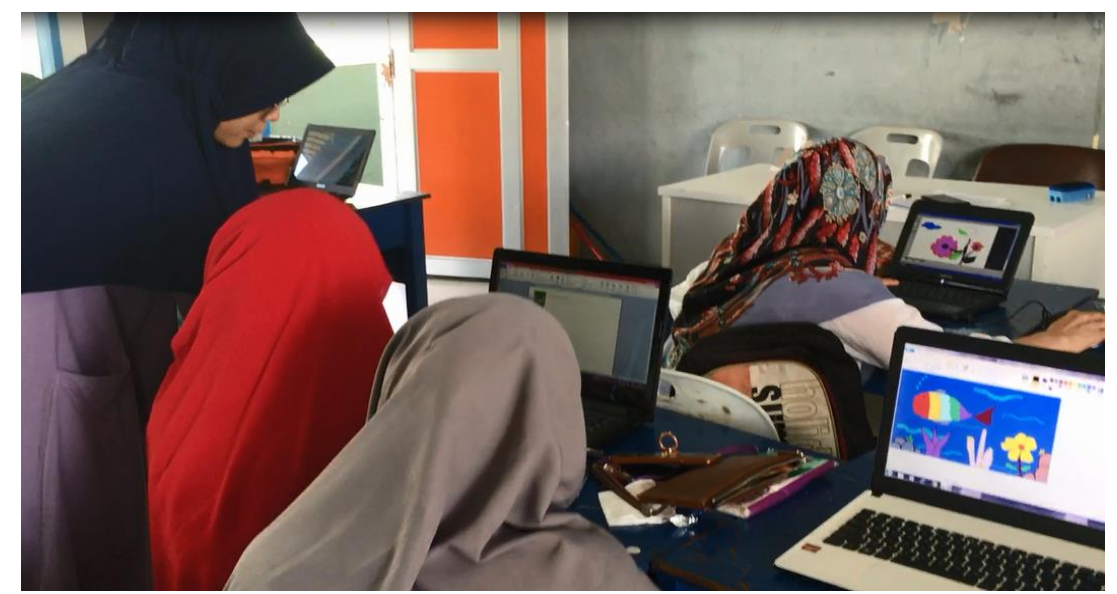

Gambar 1. Tim pengabdi mengenalkan aplikasi Paint kepada peserta

\section{Pembahasan}

Materi pertama dari pengabdian yang dilaksanakan ini adalah mengenai aplikasi Paint yang tersedia gratis pada setiap komputer atau laptop jika menggunakan OS Windows. Tujuan dari pemaparan materi ini untuk memberikan inovasi baru bagi para anggota HIMPAUDI yang keseluruhannya merupakan guru TK dan PAUD. Inovasi tersebut yakni dengan memanfaatkan teknologi informasi. Meskipun hanya guru TK atau PAUD, sudah seharusnya para anggota HIMPAUDI mampu menggunakan teknologi dalam proses belajar mengajar agar tidak membosankan. Selanjutnya materi kedua adalah mengenai pembuatan blog. Dalam materi ini hanya sampai pada login ke blog. Tujuan pengenalan blog ini sebagai wadah para anggota HIMPAUDI untuk sharing mengenai proses belajar mengajar maupun sharing mengenai tips dan trik yang menarik dalam proses belajar mengajar.

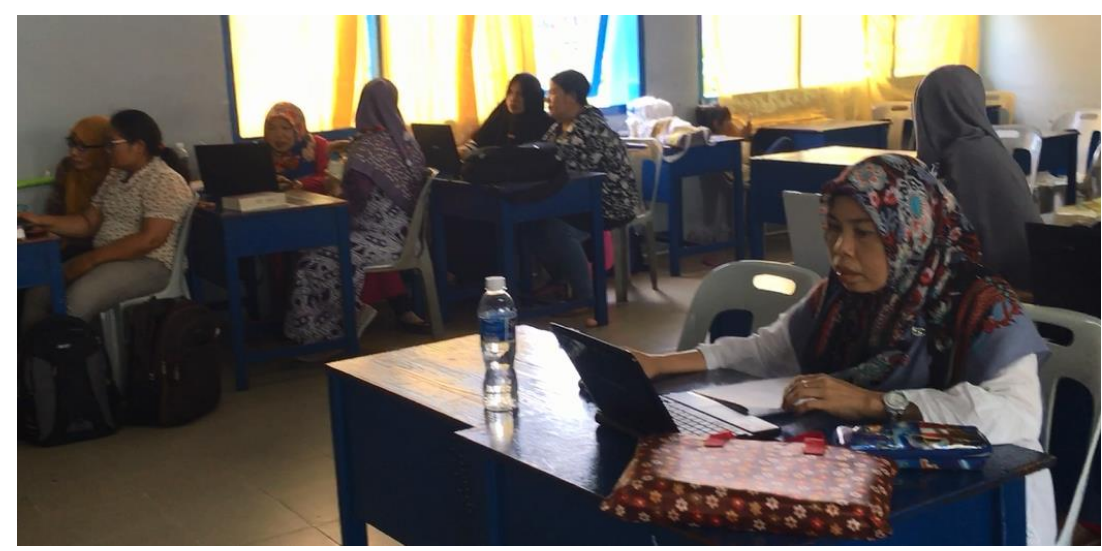

Gambar 2. Peserta mempraktekkan materi yang didapat dari tim pengabdi

Keseluruhan dari pengabdian ini dapat dilihat dari 2 aspek yang sangat mempengaruhi yaitu aspek pendukung dan aspek penghambat. Adapun penjelasan dari kedua aspek tersebut adalah sebagai berikut:

a. Aspek Pendukung

Aspek yang mendukung dari pengabdian ini diantaranya adalah adanya dukungan penuh dari para anggota HIMPAUDI yang ditunjukan dari antusias dan keaktifan ketika pelaksanaan pengabdian berlangsung. Selain itu, para peserta juga dengan senang hati membawa laptop masing-masing untuk mempermudah dalam kegiatan pengabdian.

b. Aspek Penghambat

Ada beberapa aspek yang menghambat saat berlangsungnya pengabdian ini diantaranya, koneksi internet yang belum memadai, karena tidak tersedianya wifi sehingga hanya mengandalkan koneksi dari smartphone. 


\section{KESIMPULAN}

Azwanti dkk.

Berdasarkan dari pelaksanaan pengabdian kepada masyarakat mengenai aplikasi Paint dan blog, dapat disimpulkan bahwa kegiatan telah diselenggarakan dengan baik dan berjalan dengan lancar. Adapun 2 materi tersebut telah diberikan dan dapat dipahami dengan baik oleh para peserta yang merupakan anggota HIMPAUDI Batam Center. Keaktifan serta keinginan untuk belajar dari para peserta juga menunjukan respon yang positif sehingga pengabdian ini dapat terlaksana dengan baik dan lancar.

\section{UCAPAN TERIMA KASIH}

Terima kasih tim pengabdi ucapkan kepada LPPM Universitas Putera Batam, HIMPAUDI Batam Center, dan seluruh pihak yang terlibat.

\section{Daftar Pustaka}

1. Febrialismanto. 2017. Analisis Kompetensi Profesional Guru PG PAUD Kabupaten Kampar Provinsi Riau. Jurnal Trunojoyo Universitas Negeri Yogyakarta 6(2): 121-136

2. Miranda, D. 2016. Upaya Guru Dalam Mengembangkan Kreativitas Anak Usia Dini di Kota Pontianak. Jurnal Pembelajaran Prospektif 1(1): 60-67

3. Sopiah, C. 2014. Kreatifitas Guru Paud dalam Kegiatan Belajar Mengajar. MAJALAH ILMIAH PAWIYATAN 21(1): 13-21

4. Tedjawati, J.M. 2011. Peran HIMPAUDI dalam Pengembangan PAUD. Jurnal Pendidikan dan Kebudayaan 17(1): 123-133. https://doi.org/10.24832/jpnk.v17i1.12 